\title{
Kegiatan Outbound untuk Membangkitkan Semangat Teamwork dan Menambah Energi yang Baru Pada Anggota MDMC Pangandaran
}

\author{
N H Anggarasari ${ }^{1 *}$, R S Dewi ${ }^{2}$ \\ ${ }^{12}$ Universitas Muhammadiyah Tasikmalaya \\ Email:*nandhini.hagrs@umtas.ac.id
}

\begin{abstract}
ABSTRAK
MDMC (Muhammadiyah Disaster Management Center) merupakan salah satu lembaga penanganan bencana di bawah persyarikatan Muhammadiyah. Salah satu MDMC, yang berada di Pangandaran kurang memiliki relawan-relawan yang berasal dari kader-kader ortom Muhammadiyah. Hal ini disebabkan karena kurangnya kerjasama dengan ortom dan kurangnya sosialisasi tentang bencana. Oleh karena itu, Penulis menawarkan solusi untuk menjalin kerja kerjasama dengan semua ortom Muhammadiyah se Kabupaten Pangandaran, melakukan outbound guna menambah kerjasama, dan memberikan sosialisasi tentang kebencanaan. Kegiatan pengabdian masyarakat ini meliputi materi tentang sosialisasi bencana di Pangandaran, menggali potensi dan kekurangan setiap organisasi, pentingnya kerjasama dan komunikasi secara internal maupun eksternal pada organisasi, dan pelatihan vertical rescue untuk menambah wawasan dan energi baru tentang salah satu keterampilan yang perlu dimiliki oleh relawan bencana. Pengabdian masyarakat ini memberikataan dampak yang positif bagi anggota MDMC. Kerjasama yang terbina dalam lembaga, memotivasi anggota untuk menjalin kerjasama dengan organisasi lain dan menumbuhkan semangat dan ide baru untuk bekerjasama dalam kegiatan kemanusiaan khususnya terkait bencana di Pangandaran.
\end{abstract}

Kata Kunci: Outbound, Kerjasama, MDMC

\begin{abstract}
MDMC (Muhammadiyah Disaster Management Center) is one of the disaster management institutions under the Persyarikatan Muhammadiyah. One of the MDMCs, who were in Pangandaran lacked volunteers from Muhammadiyah's orthomal cadres. This is due to lack of collaboration with orthom and lack of socialization about disasters. Therefore, the author offers a solution to establish collaborative work with all Muhammadiyah orthoms in Pangandaran Regency, conduct outbound activities to increase cooperation, and provide socialization about disasters. The community service activities included material on disaster socialization in Pangandaran, exploring the potential and disadvantages of each organization, the importance of cooperation and communication both internally and externally on the organization, and vertical rescue training to add new insights and energy about one of the skills needed by disaster volunteers . This community service provides a positive impact on MDMC members. Collaboration built in institutions motivates members to collaborate with other organizations and fosters new enthusiasm and ideas for collaborating in humanitarian activities, especially related to the disaster in Pangandaran.
\end{abstract}

Keywords: Outbound, Teamwork, MDMC 


\section{PENDAHULUAN}

Berdasarkan hasil wawancara dengan ketua MDMC Pangandaran, Dias, MDMC di Pangandaran baru dibentuk November 2016, MDMC (Muhammadiyah Disaster Management Center) merupakan salah satu lembaga Muhammadiyah yang menangani masalah terkait kebencanaan. Kegiatan kebencanaan terbagi menjadi 4 tahapan yaitu tahap preventif, tahap tanggap bencana, tahap pemulihan, dan tahap rekontruksi. Dalam lembaga ini perlu sekali relawan-relawan yang benar-benar rela turut serta berpartisipasi dalam kegiatan terkait bencana. Relawan-relawan yang paling utama adalah seluruh kader di bawah ortom Muhammadiyah. Namun dalam kenyataannya, tidak banyak kader Muhammadiyah sendiri yang turut andil dalam kegiatan kebencanaan. Hal ini disebabkan karena kurangnya sosialisasi dan komunikasi antar ortom, baik terkait bencana maupun kegiatan lain.

Berdasarkan hasil wawancara dengan ketua PDM Kabupaten Pangandaran, Bapak Sutarman, masyarakat di Kabupaten Pangandaran termasuk majemuk, ada yang merupakan warga asli dan warga pendatang. Banyak masyarakat yang masih melakukan tradisi budaya yang menurut beliau kurang sesuai dengan syariat islam. Misalnya percaya tentang klenik, percaya tentang hari baik dan buruk, dan lain-lain. Banyak warga yang masih perlu dibina tentang nilai-nilai keislaman dan diarahkan sesuai dengan syariat islam.

Berdasarkan hasil wawancara dengan pengurus Badan Wakaf Kabupaten Pangandaran, dan sekaligus kepala sekolah di SMA Muhammadiyah Pangandaran, Bapak Kosasih, masyarakat di Pangandaran banyak yang suka berdagang, kadang siswa-siswa membantu orangtuanya di hari libur, namun pengembangan AUM di Pangandaran tersendat oleh masalah komunikasi, inisiatif, dan kerjasama antar bidang. Padahal di kabupaten yang baru berkembang ini peluang usaha sangat bagus sekali. Menurut beliau lagi, kegiatan ortom pun kurang maksimal dengan baik, karena kurangnya komunikasi antar ortom dan kurangnya membangun inisiatif untuk saling kerjasama antar ortom. Selain itu juga kecenderungan masyarakat di Pangandaran yang lebih suka memandang segala sesuatu dengan materi, membuat pengkaderan Muhammadiyah agak sulit berkembang, karena sifat sukarela tanpa pamrih dan mau bekerjasama ini adalah hal yang paling penting dalam sebuah lembaga dan persyarikatan.

Berdasarkan analisa situasi yang ditemukan di Kabupaten Pangandaran, Penulis menarik kesimpulan bahwa permasalahan yang dialami oleh MDMC Pangandaran adalah kurangnya relawan yang berperan aktif dalam kegiatan yang terkait kebencanaan, relawan yang berasal dari kader-kader Muhammadiyah diseluruh ortom, karena kurangnya kerjasama antar ortom dan sosialisasi kebencanaan, dan kegiatan antar ortom belum pernah dilakukan sebelumnya.

Berdasarkan permasalah MDMC Pangandaran yang ditemukan oleh Penulis, Penulis dan tim inti MDMC Pangandaran, akan saling bekerjasama :

1. Melakukan pendekatan dan silahturahmi dengan seluruh ortom Muhammadiyah se Pangandaran.

2. Mengadakan kegiatan Outbound untuk menjalin kerjasama dan menambah energi baru untuk seluruh anggota MDMC yang terdiri dari relawan-relawan dari seluruh ortom Muhammadiyah.Kegiatan Outbound ini merupakan permainan-permainan yang dapat membangkitkan semangat kerjasama untuk menambah energi kreatif yang baru dalam tim (Jamil \& Hidayat, 2008), dan menumbuhkan kepercayaan antar anggota (Santosa \& Mulyani, 2008). Menurut Anggarasari (2012), kegiatan pelatihan merupakan salah satu cara untuk mengurangi rasa malu, diantaranya adalah pelatihan komunikasi 
interpersonal. Hal itu akan menumbuhkan jalinan komuniaksi yang lebih baik antar sesama.

3. Memberikan sosialisasi tentang kebencanaan. Materi kebencanaan merujuk pada fikih kebencanaan yang disusun berdasarkan Keputusan Musyawarah Nasional Tarjih ke 29 Tahun 2015 di Yogyakarta (2016).

\section{METODE PENELITIAN}

Pelatihan adalah proses melatih, tempat melatih. Melatih merupakan proses membiasakan diri (belajar). Seseorang dikatakan belajar bila dia berusaha memperoleh suatu ilmu pengetahuan atau keterampilan dan berlatih, yaitu belajar dan membiasakan diri agar mampu mengerjakan sesuatu, berbuat agar mnejadi biasa. (Salim,1991).

Pelatihan adalah proses, cara, perbuatan melatih, kegiatan, atau pekerjaan melatih. Sedangkan melatih adalah mengajar seseorang dan sebagainya agar terbiasa (mampu) melakukan sesuatu, membiasakan diri (belajar) (Pusat Pembinaan dan Pengembangan Bahasa, 1995)

Proses pembelajaran yang banyak mengundang partisipasi dan aktivitas peserta dilakukan agar timbulnya pemahaman yang lebih terhadap proses pembelajaran. Pelatihan merupakan proses pembelajaran untuk dapat berubah dan lebih baik, namun sebuah pembelajaran dapat menjadi tidak efektif apabila ada seorang pembelajar memiliki masalah yang sama atau masalah yang baru setelah pelatihan (di luar area pelatihan) (Leslie,2005).

Dari berbagai definisi pelatihan di atas, peneliti mengambil kesimpulan bahwa efektivitas pelatihan adalah proses atau cara membiasakan diri (belajar) yang dapat mempengaruhi sikap awal seseorang menjadi lebih baik dari sebelumnya.

Pelatihan yang dilakukan dalma pengabdian masyarakat disini adalah terdiri dari 2 tempat, yaitu di SMA Muhammadiyah Pangandaran (materi bencana dan MDMC, penggalian potensi dan kekurangan diri, kerjasama) dan di pantai batu hiu (vertical rescue).

\section{HASIL DAN PEMBAHASAN}

A. Pelaksanaan

Pelaksanaa pengabdian masyarakat yang dilakukan tim adalah :

1) Melakukan silahturahmi dengan beberapa ortom.

Dalam proses silahturahmi ini, ada beberapa hal yang ditemukan, yaitu kurangnya minat, inisiatif, dan kerelaan dalam proses terjadinya bencana pada kader Muhammadiyah. Ada sebagian kader Muhammadiyah yang hanya bersedia menyampaikan kondisi bencana, tanpa bersedia membantu meskipun secara tenaga, pikiran, maupun materi. Namun, kami dapat merangkul dua orang kader dari dua ortom untuk berpartisipasi dalam kebencanaan. Adanya kendalanya terebut, membuat kami mengubah partisipan pada rencana awal, yang tadinya semua kader Muhammadiyah, menjadi semua kader Muhamamdiyah yang aktif di kelembagaan dan ortom di tingkat sekolah menengah atas.

2) Melakukan sosialisasi dan games kerjasama.

Pada tahap ini ada 3 sesi, yaitu sosialisasi tentang bencana di Pangandaran, menggali potensi dan kekurangan diri, dan games tentang kerjasama. Saat sosialisasi, kami menyampaikan tentang kondisi kabupaten yang rawan bencana. 
Pada setahun ini telah terjadi belasan kali gempa, banjir dan longsor di beberapa tempat, puting beliung, dan berdasarkan prediksi, ada kemungkinan terjadi bencana yang lebih besar pada tahun 2018. Kabupaten Pangandaran adalah rumah bagi kita yang sekarang tinggal disana. Rumah yang terdiri dari beberapa anggota keluarga. Bila terjadi sesuatu pada rumah yang kita tinggali, kita tidak mungkin hanya selfi dan membagikan foto tersebut pada media sosial. Mungkin itu ada baiknya dalam mencari bantuan kepada orang lain, namun hal yang terpenting adalah usaha kita sendiri sebagai anggota dalam rumah untuk saling bekerjasama membantu dan menanggalkan semua kepentingan pribadi dengan diliputi rasa rela dan tulus.

Pada proses penggalian potensi dan kekurangan dalam diri, mereka diminta untuk menuliskan dan mempresentasikan potensi dan kekurangan dalam organisasi mereka, serta sumbangsih apa yang dapat mereka berikan ketika terjadi bencana. Dari pemaparan masing-masing organisasi, semua peserta tahu potensi yang dimiliki organisasi lain dan dapat saling belajar satu sama lain untuk saling melengkapi.

Pada proses games tentang kerjasama, ada dua games yang diberikan yaitu "lingkaran rumah kita" dan "tumpuan harapan". Pada "lingkaran rumah kita", peserta diminta membuat sebuah lingkaran dari kertas, dimana semua anggota kelompok dapat masuk semua berada dalam lingkaran tersebut. Peserta saling komunikasi, kerjasama, memecahkan masalah, dan menanggalkan kepentingan pribadi. Pada permainan "tumpuan harapan", peserta awalnya saling duduk di kursi, saling bercanda tawa, saling pijat memijat, membuat satu sama lain merasa nyaman, kemudian semuanya saling tidur di pangkuan peserta lainnya. Ketika semua merasa nyaman, satu persatu kursi yang menjadi tumpuan mereka dihilangkan. Peserta belajar untuk percaya pada orang lain, sekaligus memberikan tumpuan harapan pada yang lain, saling melengkapi satu sama lain, ketika materi dan kepemilikan tidak ada lagi disisi. Selain games, peserta diberi yel-yel dan lagu tentang semangat ketika terjadi bencana. Ada kita disini untuk saling membantu, ada Muhammadiyah yang akan turut berperan dalam kebencanaan.

3) Memfasilitasi anggota MDMC untuk melakukan pelatihan vertical rescue

Vertical Rescue ini diadakan oleh vertical rescue indonesia. Kami memfasilitasi anggota MDMC untuk melakukan kegiatan tersebut untuk menambah energi dan wawasan baru. Pelatihan ini dilakukanselama dua hari tiga malam di tepi pantai Batu Karas. Materinya berupa vertical rescue introduction, tools and gears, belay system, climbing calls, teknik penjangkauan, ascending-descending, knot and hitch, anchoring on hard medis, anchoring on soft media, hauling-lowering, suspension.

B. Keberlanjutan

Kegiatan pelatihan vertical rescue yang dilakukan selama dua hari tiga malam, memberikan dampak positif bagi anggota MDMC Pangandaran, yaitu timbulnya semangat baru dalam melatih dan terus menempa diri, terbukanya jalinan kerjasama dengan berbagai organisasi di luar Muhamamdiyah, misalnya BPBP, Pusdalop Pangandaran, Tagana, dan AMS. Ada beberapa ikatan komunikasi dan keterlibatan anggota MDMC Pangandaran dalam kegiatan Pusdalop tentang mitigasi bencana di Pangandaran. Kegiatan mitigasi di sekolah-sekolah, maupun kegiatan gabungan dengan seluruh relawan se-Pangandaran yang dilakukan selama dua hari satu malam di kecamatan LangkapLancar. Selain itu, munculnya ide untuk melakukan kegiatan lintas 
alam yang terdiri dari berbagai lembaga di Pangandaran untuk saling membantu dengan tema peduli lingkungan, yang akan dilaksanakan pada tahun 2018.

\section{PENUTUP}

Kegiatan outbound ini dapat menambah semangat dan energi baru bagi anggota MDMC Pangandaran. Satu sama lain dapat memahami potensi dan kekurangannya masing-masing dan berkomitmen untuk saling membantu dalam kebencanaan, selain itu juga kegiatan ini menambah wawasan dan pengalaman baru bagi anggota MDMC di Pangandaran.

Saran untuk kegiatan pengabdian masyarakat selainjutnya adalah perlu adanya pelatihan outbound dengan tema yang berbeda, misalkan adanya water rescue, jungle rescue, untuk menambah wacana baru sebagai bekal dasar tentang respon bencana, peningkatan kerjasama, dan meningkatan energi baru kembali.

\section{UCAPAN TERIMA KASIH}

Dalam paragraf ini dihaturkan ucapan terimakasih kepada 1) Pihak Universitas Muhammadiyah Tasikmalaya yang telah memberikan dukungan berupa dana untuk kelancaran terlaksananya kegiatan pengabdian masyarakat ini, 2) Pihak Lembaga Penelitian dan Pengabdian Masyarakat (LPPM) yang telah memberikan dukungan serta bantuan dalam hal pembuatan proposal, laporan, maupun arahan dalam pengadaan kegiatan pengabdian masyakarat kami, 3) MDMC Pangandaran, 4) Para Siswa yang merupakan remaja yang menjadi peserta dalam kegiatan ini, 5) Para rekan maupun tim sebagai pelaksana dalam kegiatan ini yang telah memberikan dukungan berupa dana, tenaga maupun pikiran untuk terlaksananya acara sampai selesai.

\section{DAFTAR PUSTAKA}

Jamil S., Hidayanto T. 2008. 100 Games KreatifUntukMembangundanMembentuk Tim yang Solid. Yogyakarta :GradienMediatama.

Leslie, Rae.2005. Melibatkan Pembelajaran Secara Aktif Dalam Pendidikan dan Pelatihan. Jakarta : P.T Gramedia.

Anggarasari, N.H. 2012. Efektivitas Pelatihan Komunikasi Interpersonal Untuk Mengurangi Rasa Malu. Jurnal Intervensi Psikologi, Vol. 4 No.1. http://id.portalgaruda.org/?ref=browse $\& \bmod =$ viewjournal $\&$ journal $=8162 \&$ issue $=\%$ 20Vol.\%204,\%20No.\%201,\%20Juni\%202012

Salim, Peter, Yenny. 1991. Kamus Bahasa Indonesia Kontemporer. Jakarta : Modern English Press.

PP Muhammadiyah, MajelisTarjihdanTajdid, LPB Muhammadiyah. 2015. Fikih Kebencanaan. Yogyakarta : Penerbit Majelis Tarjih dan Tajdid Pimpinan Pusat Muhammadiyah. 
Pusat Pembinaan dan Pengembangan Bahasa Departemen Pendidikan dan Kebudayaan. 1995. Kamus Besar Bahasa Indonesia. Jakarta : Balai Pustaka.

Santosa, V.E, danMulyani,I.M. 2008. 100 PermainanKreatifuntuk Outbound dan Training. Yogyakarta :Penerbit ANDI.

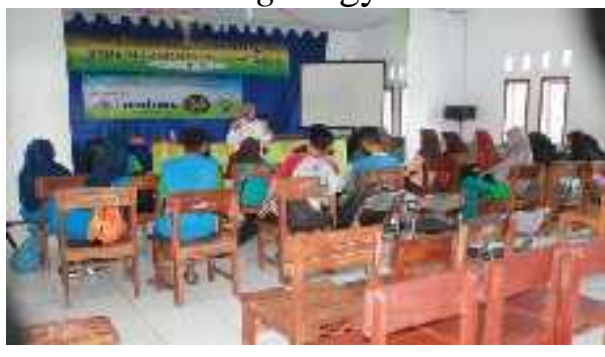

Gambar 1. Materi pengenalan bencana dan MDMC

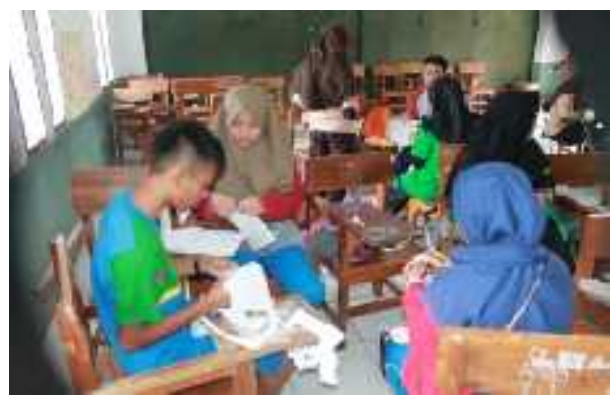

Gambar 3. Proses penyelesaian masalah tim

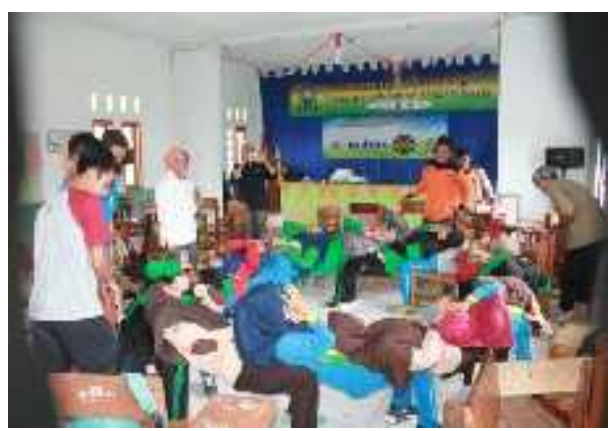

Gambar 5. Kerjasama tim wanita

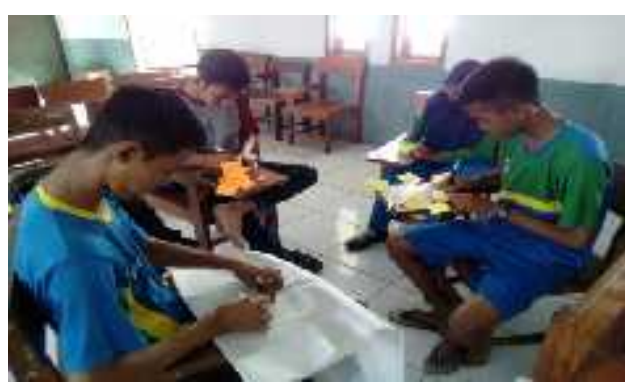

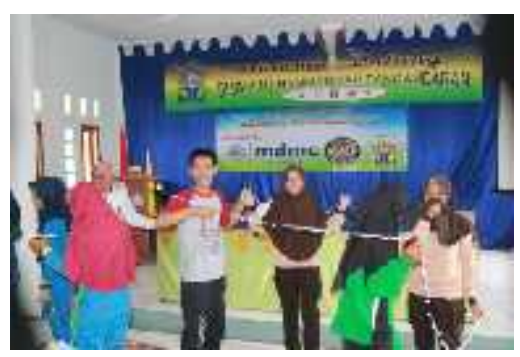

Gambar 2. Kerjasama tim dalam penyelesaian masalah

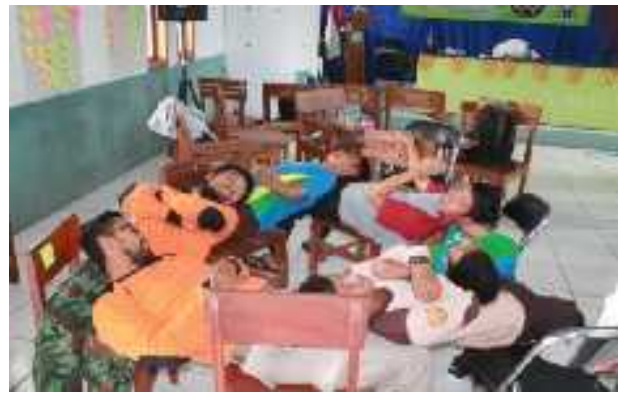

Gambar 4. Kerjasama tim laki-laki

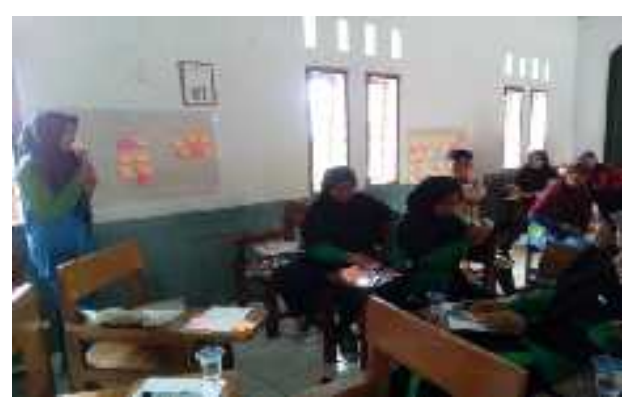

Gambar 6. Presentasi tentang potensi lembaganya terhadap bencana

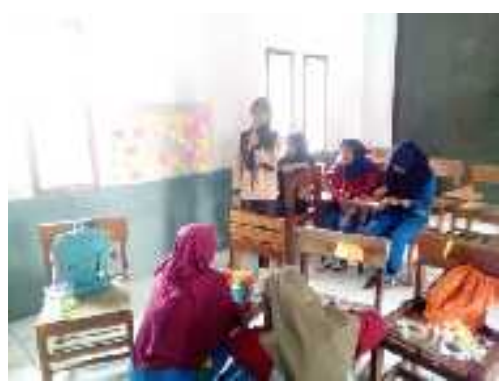


Gambar 7. Presentasi tentang potensi

lembaganya terhadap bencana

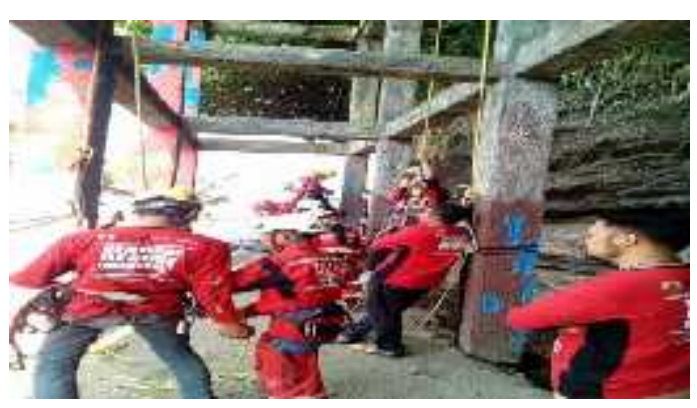

Gambar 9. Pelatihan dan praktek vertical rescue
Gambar 8. Presentasi tentang potensi lembaganya terhadap bencana

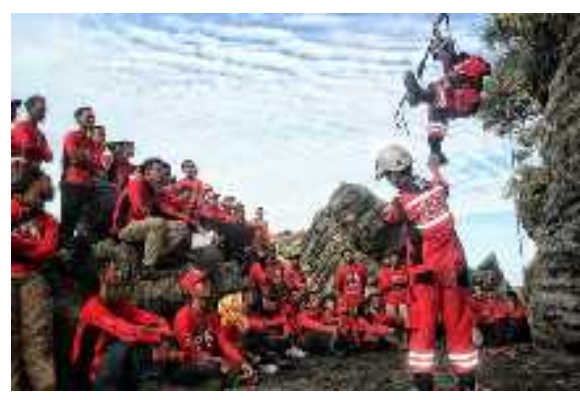

Gambar 10. Pelatihan dan praktek vertical rescue 